\title{
Tipepidine in children with attention deficit/ hyperactivity disorder: a 4-week, open-label, preliminary study
}

This article was published in the following Dove Press journal:

Neuropsychiatric Disease and Treatment

24 January 2014

Number of times this article has been viewed

\author{
Tsuyoshi Sasaki ${ }^{1,2}$ \\ Kenji Hashimoto ${ }^{3}$ \\ Masumi Tachibana' \\ Tsutomu Kurata' \\ Keiko Okawada' \\ Maki Ishikawa' \\ Hiroshi Kimura ${ }^{2}$ \\ Hideki Komatsu \\ Masatomo Ishikawa ${ }^{2}$ \\ Tadashi Hasegawa ${ }^{2}$ \\ Akihiro Shiina' \\ Tasuku Hashimoto ${ }^{2}$ \\ Nobuhisa Kanahara ${ }^{3}$ \\ Tetsuya Shiraishi \\ Masaomi lyo ${ }^{1-3}$ \\ 'Department of Child Psychiatry, \\ Chiba University Hospital, \\ ${ }^{2}$ Department of Psychiatry, Chiba \\ University Graduate School of \\ Medicine, ${ }^{3}$ Division of Clinical \\ Neuroscience, Chiba University \\ Center for Forensic Mental Health, \\ Chiba, Japan
}

Background: Tipepidine (3-[di-2-thienylmethylene]-1-methylpiperidine) has been used solely as a nonnarcotic antitussive in Japan since 1959. The safety of tipepidine in children and adults has already been established. It is reported that tipepidine inhibits G-protein-coupled inwardly rectifying potassium (GIRK)-channel currents. The inhibition of GIRK channels by tipepidine is expected to modulate the level of monoamines in the brain. We put forward the hypothesis that tipepidine can improve attention deficit/hyperactivity disorder (ADHD) symptoms by modulating monoaminergic neurotransmission through the inhibition of GIRK channels. The purpose of this open-label trial was to confirm whether treatment with tipepidine can improve symptoms in pediatric patients with ADHD.

Subjects and methods: This was a 4-week, open-label, proof-of-efficacy pilot study for pediatric subjects with ADHD. Ten pediatric ADHD subjects ( $70 \%$ male; mean age, 9.9 years; combined [inattentive and hyperactive/impulsive] subtype, $n=7$; inattentive subtype, $n=3$; hyperimpulsive subtype, $\mathrm{n}=0$ ) received tipepidine hibenzate taken orally at $30 \mathrm{mg} / \mathrm{day}$ for 4 weeks. All subjects were assessed using the ADHD Rating Scale IV (ADHD-RS), Japanese version, and the Das-Naglieri Cognitive Assessment System (DN-CAS), Japanese version.

Results: A comparison of baseline scores and 4-week end-point scores showed that all the ADHD-RS scores (total scores, hyperimpulsive subscores, and inattentive subscores) improved significantly $(P<0.001)$. Furthermore, a comparison of baseline DN-CAS total scores and 4 -week end-point scores showed a mild trend of improvement $(P=0.093)$. Tipepidine was well tolerated, with no patients discontinuing medication because of side effects.

Conclusion: Our pilot study suggests that tipepidine therapy may prove to be an effective alternative treatment for pediatric patients with ADHD. Nonetheless, more detailed randomized, double-blind trials are needed to confirm tipepidine's efficacy.

Keywords: attention deficit/hyperactivity disorder, tipepidine, GIRK channel, pediatric, antitussive, nucleus accumbens

\section{Introduction}

Attention deficit/hyperactivity disorder (ADHD) is a common chronic psychiatric disorder, characterized by a pattern of developmentally inappropriate inattention, motor restlessness, and impulsivity, which affects between 3\% and 7\% of schoolage children. ${ }^{1}$ Prospective follow-up studies found that approximately $50 \%$ of children with ADHD show symptoms that continue into adulthood, and when left untreated are associated with substance abuse, depression, unemployment, and criminal offenses. ${ }^{2,3}$

Clinical guidelines on the pharmacological treatment of ADHD recommend psychostimulants (eg, methylphenidate, dexamphetamine, mixed amphetamine salts,
Correspondence: Tsuyoshi Sasaki

Department of Child Psychiatry, Chiba

University Hospital, Inohana I-8-I, Chiba

260-8670, Japan

Tel/fax +8I 432262297

Email sasaki@faculty.chiba-u.jp 
lisdexamphetamine) and selective norepinephrine-reuptake inhibitors, such as atomoxetine. ${ }^{4}$ Psychostimulants are known to increase synaptic dopamine concentrations through inhibition of the dopamine transporter, a mechanism that facilitates dopamine reuptake into presynaptic neurons. ${ }^{5}$ Selective norepinephrine-reuptake inhibitors increase extracellular levels of norepinephrine and dopamine in the prefrontal cortex. ${ }^{6}$ This accumulating evidence suggests that behavioral problems associated with ADHD may be related to cognitive dysfunction and early disturbances in dopaminergic innervation of basal ganglia and the frontal lobe. ${ }^{7}$ Genetic and molecular studies of ADHD also demonstrate an association between this disease and dopamine-related genes. $^{7-12}$ However, psychostimulants induce a variety of side effects, including anorexia, headaches, stomach aches, insomnia, pyrexia, and tics. ${ }^{13}$ Moreover, the frequency of suicidal ideation was greater among atomoxetine-treated patients compared with placebo groups. ${ }^{14}$ These results highlight the need to identify new therapies for ADHD, particularly treatment with fewer side effects than currently available drugs.

Tipepidine (3-[di-2-thienylmethylene]-1-methylpiperidine) has been used as a nonnarcotic antitussive in Japan since 1959. The safety of tipepidine in children and adults has already been established. Furthermore, suicide-related side effects have not been documented for tipepidine. It is reported that tipepidine inhibits G-proteincoupled inwardly rectifying potassium (GIRK)-channel currents. ${ }^{15}$ The activation of the GIRK channels causes membrane hyperpolarization through potassium efflux. The inhibition of GIRK channels by tipepidine is expected to modulate the level of monoamines in the brain, since GIRK channels are coupled with G-protein-coupled receptors, including 5-hydroxytryptamine $(5-\mathrm{HT})_{1 \mathrm{~A}}$, adrenaline $\alpha_{2}$ and dopamine $\mathrm{D}_{2}$ receptors. ${ }^{15}$ Using in vivo microdialysis, Kawaura et al demonstrated that tipepidine increases the levels of 5-HT and catecholamines, including dopamine, in the prefrontal cortex of rats. ${ }^{16}$ Furthermore, Fujieda et al ${ }^{17}$ showed that tipepidine could attenuate the hyperactivity induced in methamphetamine-treated mice (an ADHD model) by modulating these monoamine systems. Given these results, we put forward the hypothesis that tipepidine can improve ADHD symptoms by modulating monoaminergic neurotransmission through the inhibition of GIRK channels coupled with monoamine receptors in the brain. The purpose of this open trial was to confirm whether treatment with tipepidine could improve symptoms in pediatric patients with ADHD.

\section{Subjects and methods}

\section{Ethics statement}

The ethics committee of Chiba University Graduate School of Medicine approved the study protocol (G24061), and all subjects provided written informed consent for participation in the study. We registered this trial on the official database of clinical research (ClinicalTrials.gov) on April 16, 2013 (NCT01835093). ${ }^{18}$

\section{Study design and subjects}

This was a 4-week, open-label, proof-of-efficacy pilot study for pediatric subjects with ADHD. The baseline demographic, clinical, and treatment characteristics of ADHD are shown in Table 1. All subjects received tipepidine hibenzate tablets. Tipepidine was taken orally at $30 \mathrm{mg}$ /day $(10 \mathrm{mg}$ after breakfast, $10 \mathrm{mg}$ after supper, and $10 \mathrm{mg}$ before bedtime), for 4 weeks. Ten pediatric subjects with ADHD were recruited from Chiba University Hospital outpatients. All subjects were diagnosed according to the Diagnostic and Statistical Manual of Mental Disorders (DSM)-IV criteria for ADHD, ${ }^{19}$ and were classified into three subtypes: combined (inattentive and hyperactive/impulsive), $n=7$; inattentive, $n=3$; and hyperimpulsive, $n=0$. Seven boys and three girls participated in this study. Seven subjects had received some drugs before entering the trial, namely methylphenidate (18-54 mg/day, $\mathrm{n}=2$ ), atomoxetine ( $75 \mathrm{mg} /$ day, $\mathrm{n}=1$ ), aripiprazole (15 mg/day, $\mathrm{n}=1$ ),

Table I Baseline demographics and clinical and treatment characteristics of ADHD subjects

\begin{tabular}{ll}
\hline Age (years \pm SD) & $9.9 \pm 2.2$ \\
Sex (male/female) & $7 / 3$ \\
Race (\% Japanese) & 100 \\
Height (cm \pm SD) & $140.5 \pm 15.5$ \\
Weight (kg $\pm S D)$ & $38.6 \pm 17.3$ \\
Tipepidine hibenzate dosage (mg/kg/day \pm SD) & $1.288 \pm 0.349$ \\
ADHD subtypes (combined/inattentive/hyperimpulsive) & $7 / 3 / 0$ \\
WISC-III/IV full IQ score $\pm S D$ & $87.4 \pm 13.3$ \\
Comorbidity (n) & 4 \\
$\quad$ Learning disorder & 2 \\
Tic disorder & 1 \\
Learning disorder and tic disorder & 1 \\
Pharmacotherapy (n) & 7 \\
Methylphenidate & 2 \\
Atomoxetine & $\mathrm{I}$ \\
Aripiprazole & $\mathrm{I}$ \\
Methylphenidate and atomoxetine & $\mathrm{I}$ \\
Atomoxetine and aripiprazole & $\mathrm{I}$ \\
Methylphenidate and risperidone & $\mathrm{I}$ \\
Näive & 3 \\
\hline
\end{tabular}

Note: Reported values are means \pm standard deviation $(n=10)$ or percentages. Abbreviations: ADHD, attention deficit/hyperactivity disorder; WISC-III/IV, Wechsler Intelligence Scale for Children III/IV; SD, standard deviation; IQ, intelligence quotient. 
a combination of methylphenidate and atomoxetine (18 and $60 \mathrm{mg} /$ day, respectively, $\mathrm{n}=1$ ), a combination of atomoxetine and aripiprazole ( 35 and $9 \mathrm{mg}$ /day, respectively, $\mathrm{n}=1$ ), and a combination of methylphenidate and risperidone (18 and $6 \mathrm{mg} /$ day, respectively, $\mathrm{n}=1$ ), while three subjects were drug-naïve. Treatment with these drugs was stable for the 4 weeks prior to enrollment, and was stable during the trial. The Mini-International Neuropsychiatric Interview for Children and Adolescents (MINI-KID) ${ }^{20}$ was conducted to exclude any current, past, personal, or familial history of mental illness. Two subjects were also diagnosed as having a learning disorder: one subject was diagnosed with tic disorders, and one with learning and tic disorders, according to the DSM-IV criteria. ${ }^{19}$

\section{Measurement of clinical symptoms}

All patients were assessed using the ADHD Rating Scale IV (ADHD-RS), Japanese version. ${ }^{21}$ The ADHD-RS is a reliable and easy-to-administer instrument both for diagnosing ADHD in children and adolescents and for assessing treatment response. It consists of 18 items, with the scale being linked directly to DSM-IV diagnostic criteria for ADHD. ${ }^{22}$ The Das-Naglieri Cognitive Assessment System (DN-CAS), Japanese version, ${ }^{23}$ was used to assess cognitive function. The DN-CAS is an assessment battery designed to evaluate cognitive processing. It was developed to integrate theoretical and applied psychological knowledge, using cognitive processing theory and tests, designed to measure planning, attention, and simultaneous and successive processing (PASS) in individuals aged 5-17 years. The Wechsler Intelligence Scale for Children third/fourth editions (WISC-III/IV), ${ }^{24,25}$ Japanese versions, were used to assess the full intelligent quotient of all patients.

\section{Statistical analysis}

Statistical analyses were performed using the software package SPSS version 21.0 for Macintosh (IBM Armonk, NY, USA). The data show means \pm standard deviation. Student's paired $t$-test was used to compare changes from baseline to 4 weeks. The Wilcoxon signed-rank test was used as a post hoc test to compare changes from baseline to 4 weeks. Values of $P<0.05$ were considered statistically significant.

\section{Results}

The baseline scores and mean changes of primary and secondary outcomes from the 4-week trial of tipepidine in ADHD subjects are shown in Table 2. A comparison of baseline scores and 4-week end-point scores showed
Table 2 Baseline scores and mean changes of primary and secondary outcomes after a 4-week trial of tipepidine in ADHD subjects

\begin{tabular}{llll}
\hline & $\begin{array}{l}\text { Baseline } \\
\text { mean } \pm \text { SD }\end{array}$ & $\begin{array}{l}\text { Week } 4 \\
\text { mean } \pm \text { SD }\end{array}$ & $\begin{array}{l}\text { P-value } \\
\text { (df, } t \text {-score })\end{array}$ \\
\hline $\begin{array}{l}\text { ADHD-RS total score } \\
\text { ADHD-RS }\end{array}$ & $30.2 \pm 9.9$ & $16.4 \pm 8.4$ & $<0.00 I^{*}(9,11.8)$ \\
$\begin{array}{l}11.2 \pm 7.1 \\
\text { hyperimpulsive } \\
\text { subscore }\end{array}$ & $5.0 \pm 4.1$ & $<0.00 I^{*}(9,5.7)$ \\
$\begin{array}{l}\text { ADHD-RS } \\
\text { inattentive }\end{array}$ & $19.0 \pm 3.6$ & $10.6 \pm 3.8$ & $<0.001 *(9,10.6)$ \\
subscore & & & \\
DN-CAS total score & $81.1 \pm 20.0$ & $87.6 \pm 21.6$ & $0.093(9,-1.88)$ \\
$\begin{array}{l}\text { DN-CAS planning } \\
\text { subscore }\end{array}$ & $89.2 \pm 16.6$ & $94.0 \pm 16.4$ & $0.164(9,-1.52)$ \\
$\begin{array}{l}\text { DN-CAS attention } \\
\text { subscore }\end{array}$ & $81.3 \pm 22.4$ & $89.5 \pm 23.1$ & $0.262(9,-1.20)$ \\
$\begin{array}{l}\text { DN-CAS } \\
\text { simultaneous }\end{array}$ & $83.8 \pm 18.3$ & $91.8 \pm 25.0$ & $0.137(9,-1.63)$ \\
$\begin{array}{l}\text { subscore } \\
\text { DN-CAS }\end{array}$ & $89.8 \pm 20.0$ & $89.9 \pm 14.4$ & $0.981(9,-0.03)$ \\
successive subscore & & & \\
\hline
\end{tabular}

Notes: $* P<0.05$. Student's paired $t$-test was used to compare changes from baseline to 4 weeks. Wilcoxon signed-rank test was used as a post hoc test to compare changes from baseline to 4 weeks.

Abbreviations: ADHD, attention deficit/hyperactivity disorder; SD, standard deviation; $d f$, degrees of freedom; ADHD-RS, Attention Deficit/Hyperactivity Disorder-Rating Scale IV (Japanese version); DN-CAS, Das-Naglieri Cognitive Assessment System (Japanese version).

that all the ADHD-RS scores (total scores, hyperimpulsive subscores, and inattentive subscores) improved significantly $(P<0.001)$. The Wilcoxon signed-rank test also detected statistical significance in all ADHD-RS scores $(P<0.005)$. However, a comparison of baseline scores and 4-week endpoint scores found that none of the DN-CAS scores (total scores and planning, attention, simultaneous, and successive subscores) showed significant change. The Wilcoxon signedrank test also failed to detect statistical significance in any DN-CAS score changes.

Tipepidine was well tolerated, with no patients discontinuing medication because of side effects. No significant effects were revealed in blood parameters, urine analysis, weight, height, blood pressure, or cardiac frequency during the 4-week follow-up period.

\section{Discussion}

Tipepidine improved the ADHD symptoms of inattention and hyperimpulsivity, as shown by ADHD-RS scores. To our knowledge, this is the first report demonstrating the beneficial effect of tipepidine in treating pediatric ADHD subjects.

Comparisons of all baseline DN-CAS scores (total scores and planning, attention, simultaneous, and successive subscores) and 4-week end-point scores detected no 
significant differences. However, a comparison of baseline DN-CAS total scores and 4-week end-point scores did show a mild trend of improvement $(P=0.093)$.

The lower improvement in DN-CAS symptomatology may have been partly due to the relatively low dosage of tipepidine used in this study $(1.288 \pm 0.349 \mathrm{mg} / \mathrm{kg} /$ day, Table 1), compared with that of the Fujieda et al trial in mice $(20 \mathrm{mg} / \mathrm{kg}) .{ }^{17}$ Higher dosages may be more beneficial for ADHD symptoms, as they are associated with higher monoaminergic neurotransmission through GIRK channels. At present, the optimal dosage of tipepidine for ADHD is unknown, and defining this dosage should be the primary focus in the treatment of these patients.

The inhibition of GIRK channels by tipepidine is predicted to modulate brain monoamine levels in a similar manner to psychostimulants and selective norepinephrinereuptake inhibitors. However, this trial found none of the side effects typically associated with psychostimulants and selective norepinephrine-reuptake inhibitors. Tipepidine has been used safely as an over-the-counter antitussive for children and adults in Japan since 1959. Therefore, safety issues will be no of no concern if this is used as a new treatment for ADHD.

Very recently, Hamasaki et al showed that tipepidine activated dopamine neurons in the ventral tegmental area through the inhibition of GIRK channel-activated currents, and their preliminary microdialysis study showed that tipepidine dramatically increased dopamine levels in the shell of the nucleus accumbens (NAc). ${ }^{26}$ In addition, Costa Dias et al identified the possible involvement of NAc connections in the pathophysiology of impulsive decision making in ADHD, using functional connectivity magnetic resonance imaging. ${ }^{27}$ Therefore, further detailed studies of tipepidine use in ADHD are needed to investigate dopamine activation in the NAc and its neural pathways.

The main limitation of this study was the small sample size $(n=10)$. The second limitation was the low proportion of drug-naïve subjects. Further studies with greater analytical power, larger sample sizes, and more drug-naïve subjects will be necessary.

\section{Conclusion}

In conclusion, our pilot study suggests that tipepidine therapy may prove to be an effective alternative treatment for pediatric patients with $\mathrm{ADHD}$, and since this drug is already in wide clinical use for other conditions, there should be no ensuing safety issues. However, the safety of long-term tipepidine use needs to be evaluated carefully, since many antitussive medications are completed within 1 week. Nonetheless, more detailed randomized, double-blind studies are needed to confirm tipepidine's efficacy and safety.

\section{Author contributions}

$\mathrm{T}$ Sasaki and $\mathrm{K}$ Hashimoto drafted the manuscript. $\mathrm{K}$ Hashimoto is the principal investigator of this study. All authors recruited the patients, revised the article, conducted the statistical analysis, approved the final manuscript, and agreed to be accountable for all aspects of the work.

\section{Acknowledgments}

The authors are very grateful to Aya Tano and Nao Miyazaki (Chiba University), for their valuable advice on the use of DN-CAS. The authors thank Kaoru Ikeda, Chisako Fujishiro, Kimika Akiba, Natsuko Tateshouji, Komako Ito (Chiba University), the staff of the Department of Pharmacy, Chiba University Hospital, and Chiba University Hospital Clinical Research Center for their assistance with this trial.

\section{Disclosure}

The authors report no conflicts of interest in this work.

\section{References}

1. Polanczyk G, de Lima MS, Horta BL, Biederman J, Rohde LA. The worldwide prevalence of ADHD: a systematic review and metaregression analysis. Am J Psychiatry. 2007;164:942-948.

2. Biederman J, Mick E, Surman C, et al. A randomized, placebocontrolled trial of OROS methylphenidate in adults with attentiondeficit/hyperactivity disorder. Biol Psychiatry. 2006;59:829-835.

3. Molina BS, Hinshaw SP, Swanson JM, et al. The MTA at 8 years: prospective follow-up of children treated for combined-type ADHD in a multisite study. J Am Acad Child Adolesc Psychiatry. 2009;48: 484-500.

4. Seixas M, Weiss M, Müller U. Systematic review of national and international guidelines on attention-deficit hyperactivity disorder. J Psychopharmacol. 2012;26:753-765.

5. Solanto MV. Neuropsychopharmacological mechanisms of stimulant drug action in attention-deficit hyperactivity disorder: a review and integration. Behav Brain Res. 1998;94:127-152.

6. Bymaster FP, Katner JS, Nelson DL, et al. Atomoxetine increases extracellular levels of norepinephrine and dopamine in prefrontal cortex of rat: a potential mechanism for efficacy in attention deficit/hyperactivity disorder. Neuropsychopharmacology. 2002;27:699-711.

7. Gill M, Daly G, Heron S, Hawi Z, Fitzgerald M. Confirmation of association between attention deficit hyperactivity disorder and a dopamine transporter polymorphism. Mol Psychiatry. 1997;2:311-313.

8. Cook EH Jr, Stein MA, Krasowski MD, et al. Association of attentiondeficit disorder and the dopamine transporter gene. Am J Hum Genet. 1995;56:993-998.

9. LaHoste GJ, Swanson JM, Wigal SB, et al. Dopamine D4 receptor gene polymorphism is associated with attention deficit hyperactivity disorder. Mol Psychiatry. 1996;1:121-124.

10. Faraone SV, Perlis RH, Doyle AE, et al. Molecular genetics of attentiondeficit/hyperactivity disorder. Biol Psychiatry. 2005;57:1313-1323.

11. Bobb AJ, Castellanos FX, Addington AM, Rapoport JL. Molecular genetic studies of ADHD: 1991 to 2004. Am J Med Genet B Neuropsychiatr Genet. 2005;132:109-125. 
12. Li D, Sham PC, Owen MJ, He L. Meta-analysis shows significant association between dopamine system genes and attention deficit hyperactivity disorder (ADHD). Hum Mol Genet. 2006;15: 2276-2284.

13. Huang YS, Tsai MH. Long-term outcomes with medications for attention-deficit hyperactivity disorder: current status of knowledge. CNS Drugs. 2011;25:539-554.

14. Bangs ME, Tauscher-Wisniewski S, Polzer J, et al. Meta-analysis of suicide-related behavior events in patients treated with atomoxetine. J Am Acad Child Adolesc Psychiatry. 2008;47:209-218.

15. Takahama K, Shirasaki T, Soeda F. Central mechanisms III: neuronal mechanisms of action of centrally acting antitussives using electrophysiological and neurochemical study approaches. Handb Exp Pharmacol. 2009:219-240.

16. Kawaura K, Honda S, Soeda F, Shirasaki T, Takahama K. [A novel antidepressant-like action of drugs possessing GIRK channel blocking action in rats]. Yakugaku Zasshi. 2010;130:699-705. Japanese.

17. Fujieda Y, Soeda F, Shirasaki T, Takahama K. Centrally-acting antitussives depress drug-induced hyperactivity in mice. J Pharm Sci. 2006;100 Suppl 2:238.

18. Chiba University. An Open Study of Tipepidine Hibenzate in Patients With Attention Deficit Hyperactivity Disorder (ADHD). Available from: http:/clinicaltrials.gov/show/NCT01835093. NLM identifier: NCT01835093. Accessed January 10, 2014.
19. American Psychiatric Association. Diagnostic and Statistical Manual of Mental Disorders. 4th ed. Washington: American Psychiatric Publishing; 2000.

20. Sheehan DV, Sheehan KH, Shytle RD, et al. Reliability and validity of the Mini International Neuropsychiatric Interview for Children and Adolescents (MINI-KID). J Clin Psychiatry. 2010;71;313-326.

21. DuPaul GJ, Power TJ, Anastopoulos AD, Reid R. ADHD Rating Scale-IV (for Children and Adolescents): Checklists, Norms, and Clinical Interpretation. New York: Guilford; 1998.

22. Tani I, Okada R, Ohnishi M, Nakajima S, Tsujii M. Japanese version of home form of the ADHD-RS: an evaluation of its reliability and validity. Res Dev Disabil. 2010;31:1426-1433.

23. Das JP, Naglieri JA, Kirby JR. Assessment of Cognitive Process: The PASS Theory of Intelligence. Boston: Allyn and Bacon; 1994.

24. Wechsler D. Wechsler Intelligence Scale for Children. 3rd ed. New York: Psychological Corporation; 1991.

25. Wechsler D. Wechsler Intelligence Scale for Children. 4th ed. New York: Psychological Corporation; 1998.

26. Hamasaki R, Shirasaki T, Soeda F, Takahama K. Tipepidine activates VTA dopamine neuron via inhibiting dopamine D2 receptor-mediated inward rectifying $\mathrm{K}(+)$ current. Neuroscience. 2013;252:24-34.

27. Costa Dias TG, Wilson VB, Bathula DR, et al. Reward circuit connectivity relates to delay discounting in children with attention-deficit/ hyperactivity disorder. Eur Neuropsychopharmacol. 2013;23:33-45.
Neuropsychiatric Disease and Treatment

\section{Publish your work in this journal}

Neuropsychiatric Disease and Treatment is an international, peerreviewed journal of clinical therapeutics and pharmacology focusing on concise rapid reporting of clinical or pre-clinical studies on a range of neuropsychiatric and neurological disorders. This journal is indexed on PubMed Central, the 'PsycINFO' database and CAS.

\section{Dovepress}

The manuscript management system is completely online and includes a very quick and fair peer-review system, which is all easy to use. Visit http://www.dovepress.com/testimonials.php to read real quotes from published authors. 